\title{
Modelling of diesel generator operating modes on the basis of the engine speed characteristic in autonomous photovoltaic systems
}

\author{
D N Karamov 2 [0000-0001-5360-4826], I V Naumov ${ }^{2}$, D A Ivanov ${ }^{3}$ and S V Podyachikh ${ }^{3}$ \\ ${ }^{1}$ Melentiev Energy Systems Institute of Siberian Branch of RAS, Lermontov Str. 130, \\ Irkutsk, Russia, 664033 \\ ${ }^{2}$ Irkutsk National Research Technical University, Lermontov Str. 83, Irkutsk, Russia, \\ 664074 \\ ${ }^{3}$ Irkutsk State Agrarian University named after A.A. Ezhevsky, Molodezhny Str. 1/1, \\ Irkutsk district, Molodezhny settlement, Russia, 664038
}

E-mail: dmitriy.karamov@mail.ru, professornaumov@list.ru, ivanov-irk@yandex.ru psv78@yandex.ru

\begin{abstract}
The article presents a universal diesel generator model based on the processing of the engine speed characteristic. Processing uses linear interpolation with a fixed discrete step. An autonomous photovoltaic system arbitrarily located in Eastern Siberia is used as a case study. Solar radiation modelling was based on multi-year meteorological data sets using the tandem of Iqbal-Kasten/Czeplak models. The photovoltaic system under investigation consists of two $400 \mathrm{~kW}$ diesel generators (totalling $800 \mathrm{~kW}$ ) and one $375 \mathrm{~kW}$ solar power plant. In calculating the operating modes, the diesel power plant's minimum limit load factor was taken into consideration. The resulting values of the diesel generator's operating modes show the following patterns. As an example, the lesser the diesel generator's load, the lesser engine speed and the higher specific fuel consumption. The suggested model can be used in comprehensive energy research, specifically in areas such as optimal equipment configuration, operational reliability and sustainability as well as cost-efficiency.
\end{abstract}

\section{Introduction}

The integration of renewable sources of energy into energy systems considerably reduces diesel fuel consumption [1,2]. The decrease in annual diesel fuel consumption and in the number of diesel generator operating hours reduces the cost of electricity generated [3]. Reliable 24-hour power supply improves technical and economic indicators and raises the standard of living in remote communities.

A number of issues need to be addressed in order to integrate renewable sources of energy into existing autonomous energy systems. Major issues are related to determining optimal equipment configuration. The optimization process is based on the detailed mathematical model of an autonomous energy system consisting of a specific number of power generation, transmission, transformation, and accumulation elements [4].

The overall level of precision and reliability in modelling the operating modes of an energy system depends on the level of detail of its individual elements. 
This study aims to present a universal diesel generator model operating in parallel with a photovoltaic system. Using this model will make it possible to keep a detailed account of changes taking place in the unit's operating parameters, the diesel fuel consumption rate and its operating life.

\section{Analysis of natural and climatic factors}

Detailed information on natural and climatic factors is necessary in photovoltaic system modelling, and the level of detail depends on the given target. For example, the amount of solar radiation changes considerably depending on the season, month, day and time of the period under examination. Furthermore, consideration should be taken of a number of annual patterns reducing the solar radiation level due to high cloud cover during certain periods of the year $[5,6]$.

Currently, a variety of sources are available for reproducing solar radiation on a given territory. [7] provides their comprehensive description and an overview of related scientific research.

The present study uses a methodology for modelling natural and climate figures on the basis of open-source multi-year meteorological data sets. These data are in the international FM 12 Synop code form which gives both a numerical and verbal description of climate figures. The latter ones are recorded once an hour.

Multi-year meteorological data sets in FM 12 Synop and METAR code forms are processed line by line throughout meteorological measurements, and the multi-year chronology of climate events is established with a one-hour discrete step. [7] gives a full description of the methodology for processing and automatically correcting erroneous measurements and for eliminating time gaps in measurements of multi-year meteorological data sets in FM 12 Synop and METAR code forms.

The following stage involves modelling of direct, diffuse, reflected and total solar radiation on a horizontal surface. The modelling process adopts the tandem of Kasten/Czeplak mathematical models. The Iqbal (1980) model calculates total solar radiation for clear-sky conditions and, next, the Kasten/Czeplak model determines the attenuation coefficient due to cloud cover (1980). Our upcoming study shall provide an in-depth mathematical description of the above models.

Figure 1 shows a visualization multi-year meteorological data sets.
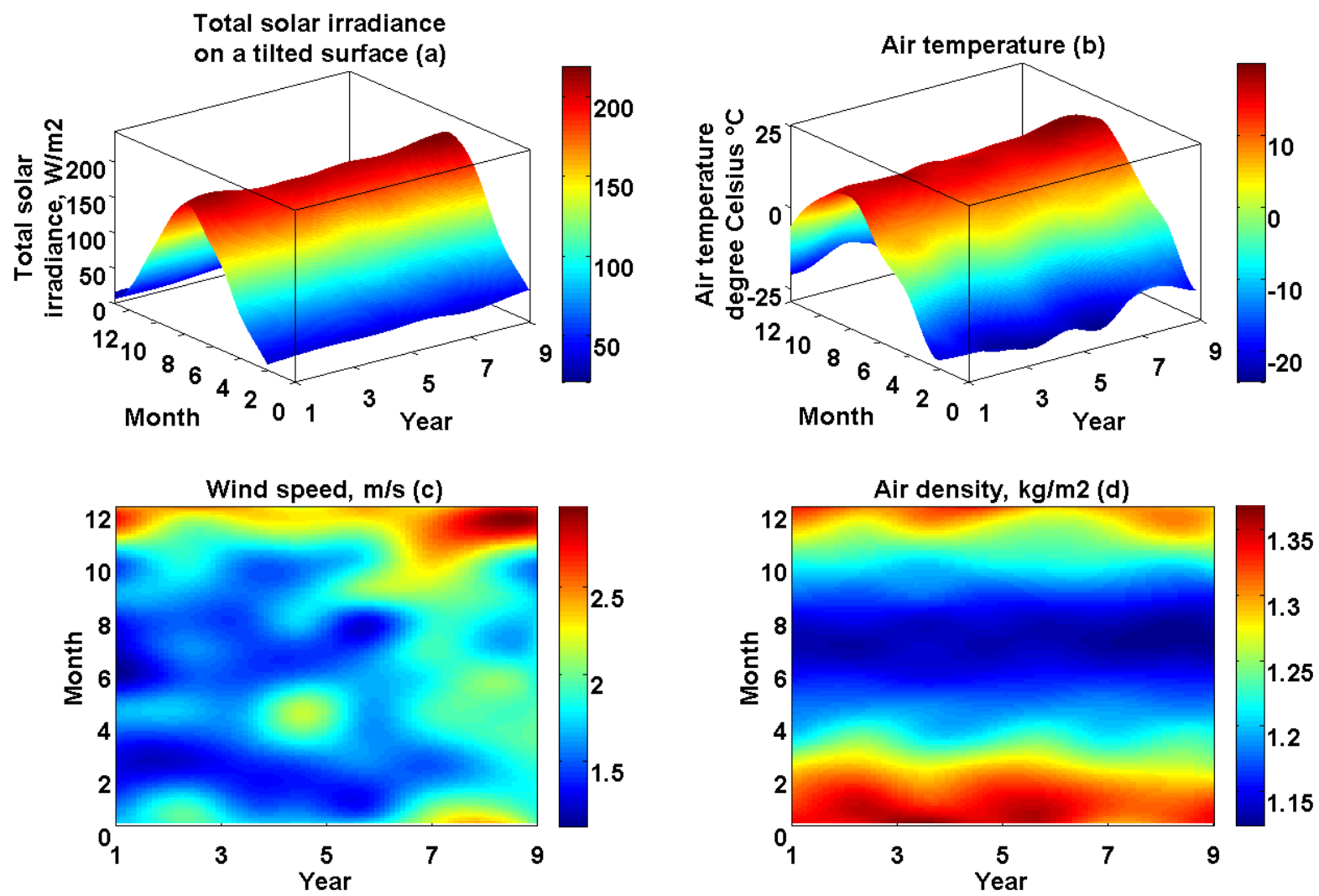

Figure 1. Visualization of multi-year meteorological data sets. 
The data provided by these models were verified in various natural and climatic areas in Eastern Siberia and Russian Far East [7, 8].

\subsection{Formation of a typical meteorological year}

A typical meteorological year is a set of meteorological data with data values for every hour in a year for a given geographical location. The data are selected from hourly data in a longer time period (normally 10 years or more). For each month in the year the data have been selected from the year that was considered most "typical" for that month. For instance, January might be from 2007, February from 2012 and so on. To determine typical meteorological year data, various meteorological measurements are made at hourly intervals over a number of years to build up a picture of the local climate. A simple average of the yearly data underestimates the amount of variability, so the month that is most representative of the location is selected. For each month, the average radiation over the whole measurement period is determined, together with the average radiation in each month during the measurement period. The data for the month that has the average radiation most closely equal to the monthly average over the whole measurement period is then chosen as the typical meteorological year data for that month. This process is then repeated for each month in the year. The months are added together to give a full year of hourly samples - Figure 2 .
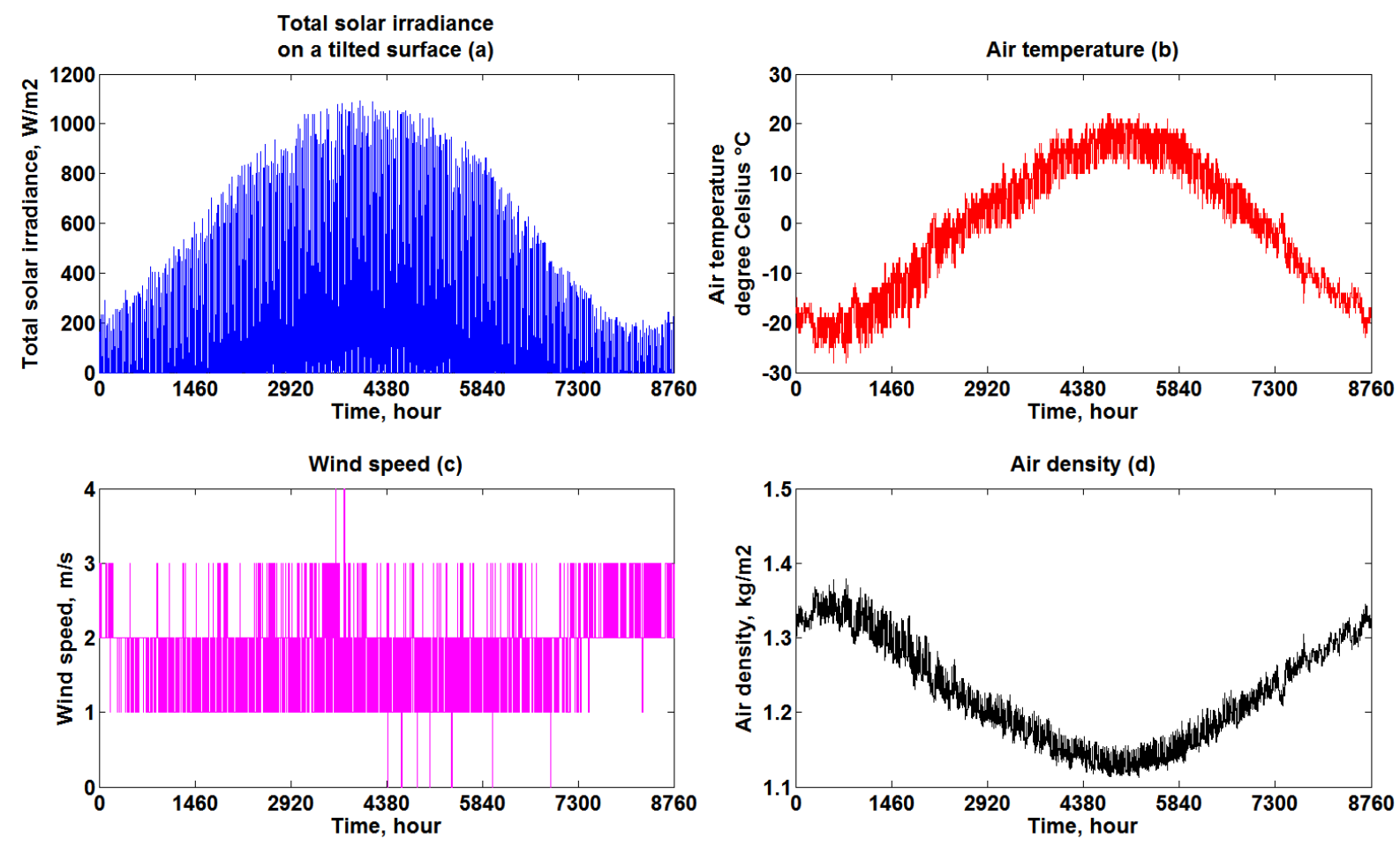

Figure 2. Climatic parameters of a typical meteorological year.

The climatic parameters of a typical meteorological year can be used in modeling the operation modes of photovoltaic systems and wind farms. Also, the parameters of a typical meteorological year can be used in predicting electric load.

\section{Autonomous photovoltaic system model}

Autonomous photovoltaic system model consist of a diesel power plant operating in parallel with a solar power plant, the diesel plant being the leading one and the solar plant the led one respectively.

This condition accounts for operational constraints reflected in the load factor of operating diesel generators which should not be inferior to $30 \%$. Automatic regulation of grid-tie inverters is what ensures observance of these constraints. This condition secures the smooth and safe operation of the entire autonomous photovoltaic system [9]. 
Therefore autonomous photovoltaic system operates according to the following algorithm:

1. If the output power of a solar power plant is sufficient to cover consumers' electric needs, it provides up to $70 \%$ of the power load.

2. If the output power of a solar power plant exceeds the acceptable power exchange limit, the gridtie inverter regulates it with respect to constraints.

3. At night, electricity is supplied only by diesel power stations.

Figure 3 shows the overview schematic diagram of an autonomous photovoltaic system.

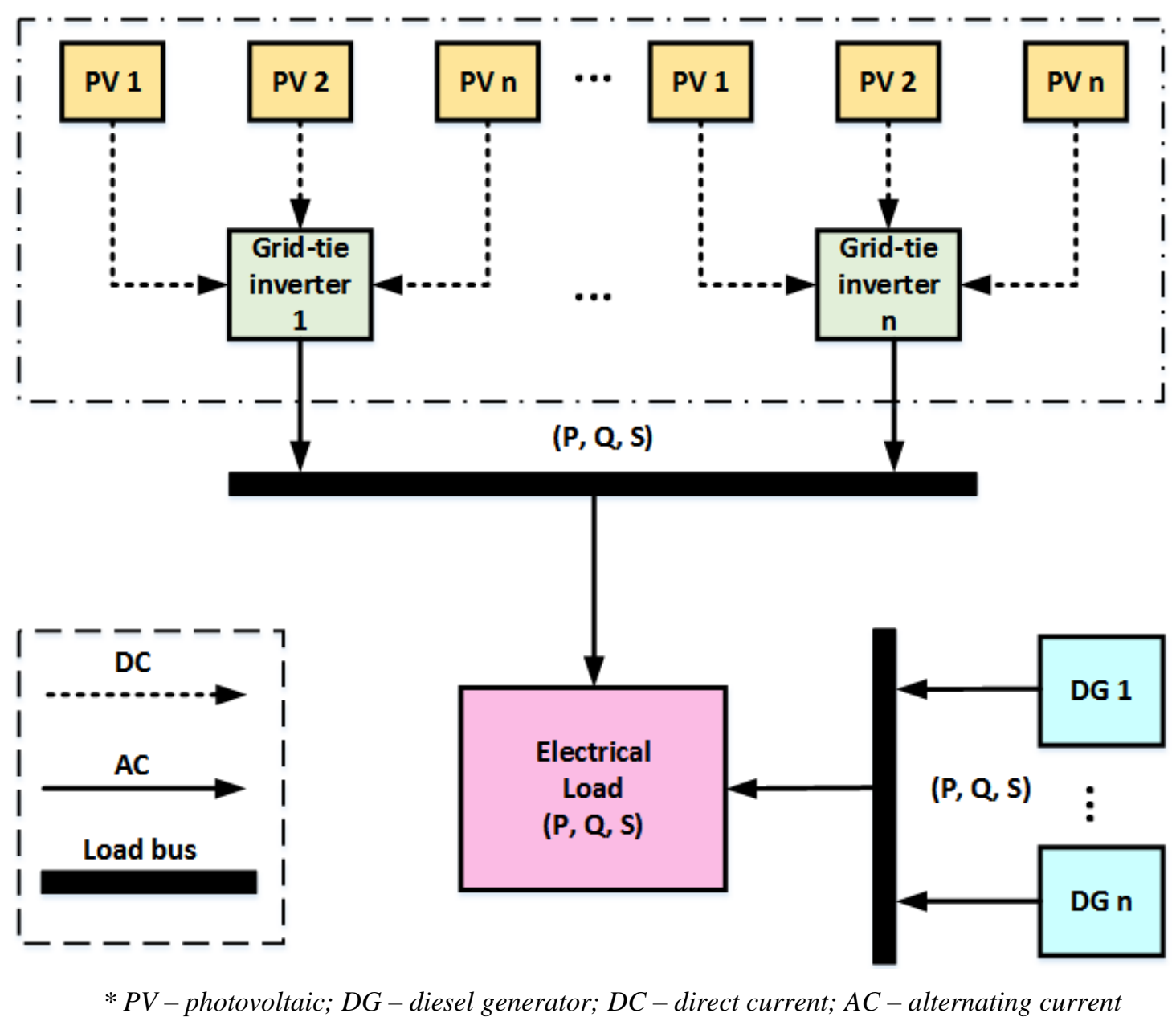

Figure 3. Simplified schematic diagram of an autonomous PV-diesel system.

The time-varying modes of operation of the photovoltaic system affect the modes of a diesel power plant such as load factor, rotational speed per minute, active power, reactive power and specific fuel consumption. Therefore, modeling of solar panels depending on climatic parameters will be presented below.

\subsection{Solar panel modelling}

This section of the article describes an algorithm for modeling solar panels. The generation level (W) is determined at the first stage of photovoltaic converter modelling.

$$
\mathrm{P}_{\mathrm{PV}}(\mathrm{t})=\overline{\mathrm{I}}_{\mathrm{A}}(\mathrm{t}) \cdot \eta(\mathrm{t}) \cdot \mathrm{A} \cdot \mathrm{k}_{\mathrm{L}},
$$

where $\overline{\mathrm{I}}_{\mathrm{A}}(\mathrm{t})$ is solar radiation incoming to the photovoltaic converter's sloping surface, $\mathrm{W} / \mathrm{m}^{2} ; \mathrm{k}_{\mathrm{L}}$ is coefficient considering power losses in diodes and taken to be 0.85-0.95 p.u. due to pollution [10].

Photovoltaic converter performance is recalculated according to solar radiation, ambient air temperature, solar panel operating temperature and wind speed. The following formula is used to to make such a recalculation (p.u.). 


$$
\eta(t)=\bar{\eta} \cdot\left[1-\beta \cdot\left(T_{P V}(t)-48\right)\right]
$$

where the photovoltaic converter's operating temperature is expressed as follows

$$
\mathrm{T}_{\mathrm{PV}}(\mathrm{t})=\mathrm{T}_{\mathrm{a}}(\mathrm{t})+\frac{\overline{\mathrm{I}}_{\mathrm{A}}(\mathrm{t})}{\mathrm{k}_{0}+\mathrm{k}_{1} \cdot \mathrm{V}_{\mathrm{w}}(\mathrm{t})} .
$$

In the above formulas, $\bar{\eta}$ is nominal value of the photovoltaic converter's efficiency, p.u.; $\beta$ is temperature coefficient for silicon photovoltaic converters $(0.004-0.006)$, p.u. ${ }^{\circ} \mathrm{C} ; \mathrm{k}_{0}, \mathrm{k}_{1}$ are Koehl correlation coefficients (30.02 and 6.28) [11]; $\mathrm{V}_{\mathrm{w}}(\mathrm{t})$ is wind speed on the surface of the Earth, $\mathrm{m} / \mathrm{s}$.

Photoelectric current (A) is calculated at the next stage.

$$
\mathrm{I}_{\mathrm{PH}}(\mathrm{t})=\frac{\overline{\mathrm{I}}_{\mathrm{A}}(\mathrm{t})}{1000} \cdot\left[\mathrm{I}_{\mathrm{SC}}+\mathrm{k}_{\mathrm{I}} \cdot\left(\mathrm{T}_{\mathrm{PV}}(\mathrm{t})-25\right)\right]
$$

where $I_{S C}$ is short circuit current of solar panel, $A$; temperature coefficient for current $k_{I}$ is taken to be 0.004 p.u. $/{ }^{\circ} \mathrm{C}$.

After determining output power and current values with regard to changing solar radiation and the photovoltaic converter's operating temperature, it is possible to determine voltage (V).

$$
\mathrm{U}_{\mathrm{PV}}(\mathrm{t})=\mathrm{P}_{\mathrm{PV}}(\mathrm{t}) / \mathrm{I}_{\mathrm{PH}}(\mathrm{t})
$$

Consequently, all the necessary operating parameters of the photovoltaic converter have been determined, including output power, output current and voltage, solar panel temperature and efficiency.

In this study, a $320 \mathrm{~W}$ heterojunction solar panel was used. Technical parameters are presented on the manufacturer's website [12].

The dynamics of the operation modes of heterojunction solar panels $(320 \mathrm{~W})$ for the typical meteorological year of Eastern Siberia is shown in Figure 4.
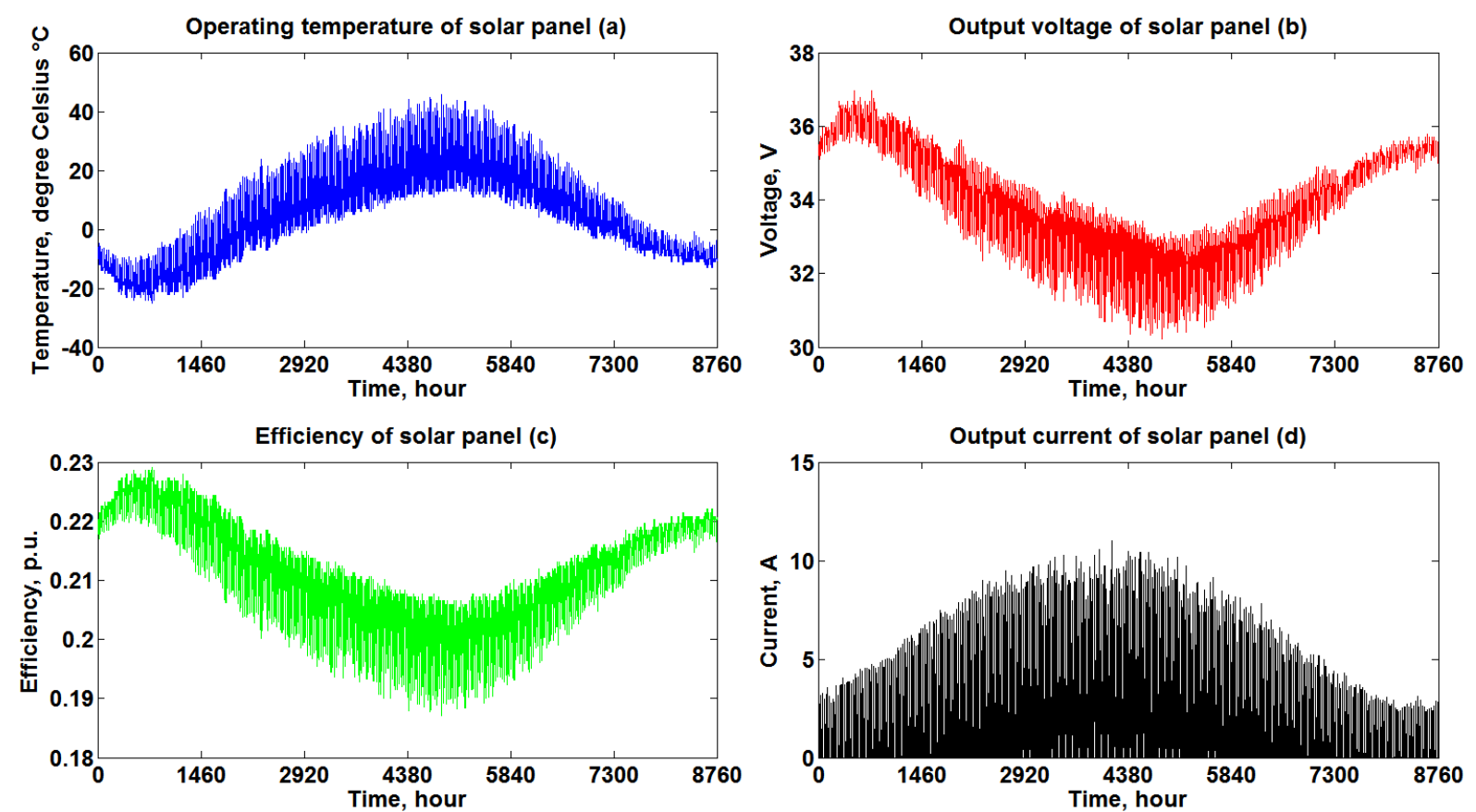

Figure 4. Operating parameters (operating temperature $-a$; voltage $-b$;

$\mathrm{c}$ - efficiency; current $-\mathrm{d}$ ) of the solar panel during the year.

Figure 4 shows the regular dynamics of the solar panel operating modes during the year. For example, as the solar radiation level changes, the output current undergo considerable changes 
whereas voltage remains virtually unchanged. At the same time, the decreasing operating temperature of the solar panels increases the efficiency and voltage respectively.

\subsection{Solar battery connection}

Based on the operating parameters of the solar panels, the connection scheme of the solar panels in the solar battery is determined. The connection scheme of solar panels in the solar battery depends on two parameters: current and voltage. Current and voltage vary greatly throughout the year. In this case, the following patterns can be noted. For example, the current of the solar panel is highly dependent on solar radiation, while the voltage is practically unchanged. In this case, the voltage of the solar panel depends on the operating temperature while the current does not change.

The connection of the solar panels is carried out in series and in parallel (mixed connection), where the series connection increases the output voltage, while the parallel connection increases the current of the solar battery. The number of solar panels connected in parallel and in series depends on the technical limitations of grid-tie inverter. The grid-tie inverter has a certain number of inputs that are characterized by maximum values of current and voltage. Therefore, it is necessary to determine such a connection scheme of solar panels under which these conditions will be observed.

Article [13] presents an algorithm for calculating the optimal connection scheme solar panels in a solar battery. Also in this article a technique for determining the installed capacity of grid-tie inverters is presented.

\subsection{Universal diesel generator model}

Diesel generators are modelled according to the data provided by the engine's speed characteristic [14]. Figure 5 (a) illustrates YaMZ-8503.10 diesel engine's speed characteristic.

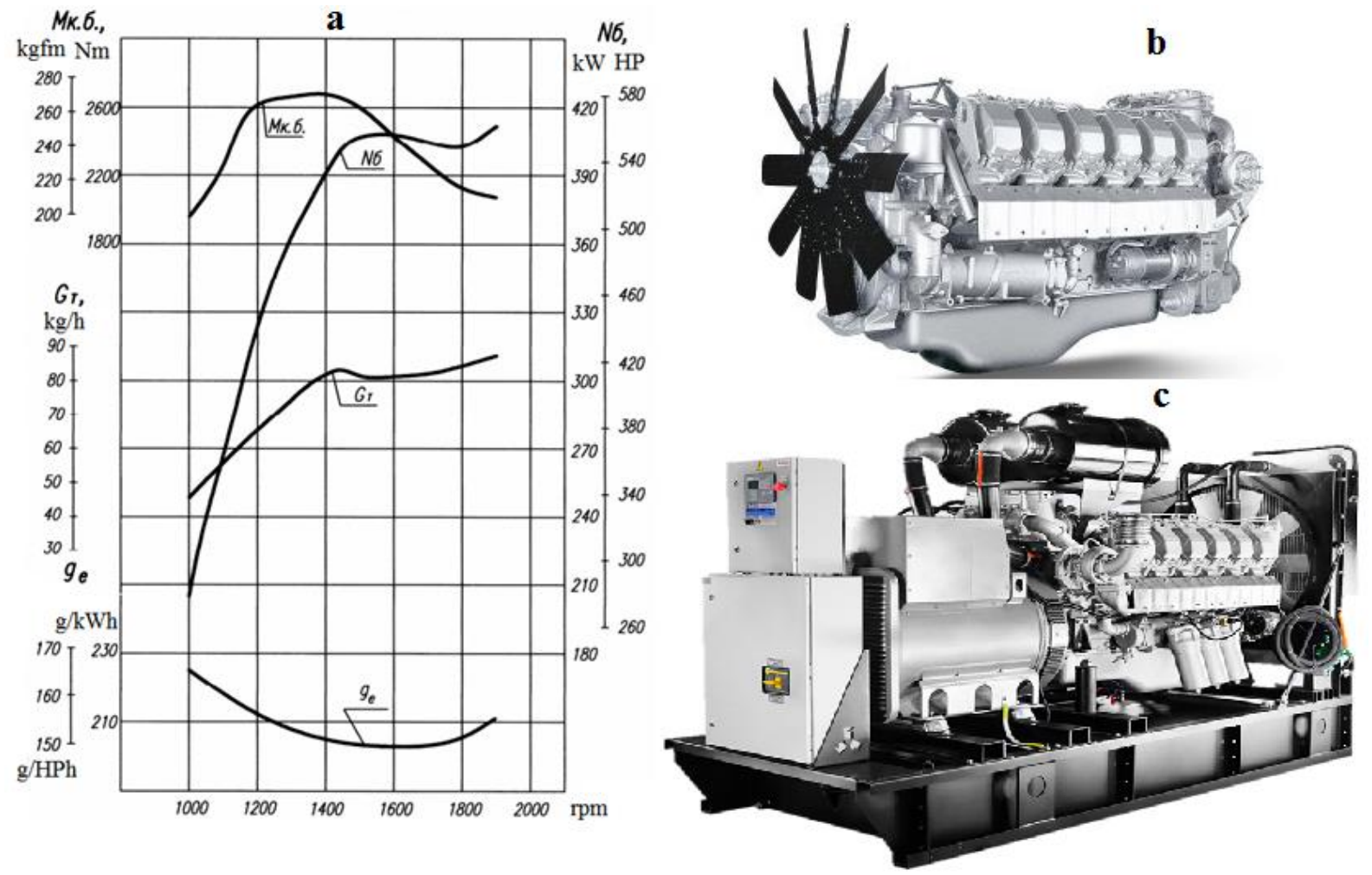

Figure 5. YaMZ-8503.10 diesel engine's speed characteristic - a; general view: diesel engine YaMZ-8503.10 - b; diesel generator $400 \mathrm{~kW}-\mathrm{c}$.

The number of steps in the speed characteristic is determined at the first stage. In the present study, the number of steps is 10 . 
Source information, namely diesel engine revolutions, specific fuel consumption and output power, are entered at the second stage.

An array of intermediate argument values with a fixed discrete step is compiled at the third stage. Linear interpolation is further applied to form diesel generator performance characteristics.

The resulting diesel engine characteristics make it possible to determine engine speed and specific fuel consumption depending on the load factor. Therefore, it is possible to determine the number of machine-hours of the diesel engine to the following formula.

$$
\mathrm{M}_{\mathrm{h}}(\mathrm{t})=\mathrm{rpm}_{\mathrm{DG}}(\mathrm{t}) / \overline{\mathrm{rpm}}
$$

where $\operatorname{rpm}_{\mathrm{DG}}(\mathrm{t})$ is the rotational speed of a diesel engine at time $t ; \overline{r p m}$ diesel engine rated speed (usually 1500).

This allows you to take into account the maintenance of diesel generators in detail, depending on their operating time.

\section{Numerical example}

A virtual autonomous photovoltaic system arbitrarily located in Eastern Siberia can be cited as an example.

The photovoltaic system's components include two $400 \mathrm{~kW}$ diesel generators (totalling $800 \mathrm{~kW}$ ) and $375 \mathrm{~kW}$ solar power plant. Grid-tie inverter installed capacity, based on the solar plant's maximum $\mathrm{PV}$ generation, is $250 \mathrm{~kW}(5 \times 50 \mathrm{~kW})$.

The minimum load factor of a diesel station is $30 \%(120 \mathrm{~kW})$. Consequently, a control algorithm for the solar plant's grid-tie inverters takes these constraints into consideration.

As a result, all the necessary requirements for a diesel plant to operate normally are met. Figure 6 illustrates changes in PV generation at solar and diesel plants over a year.
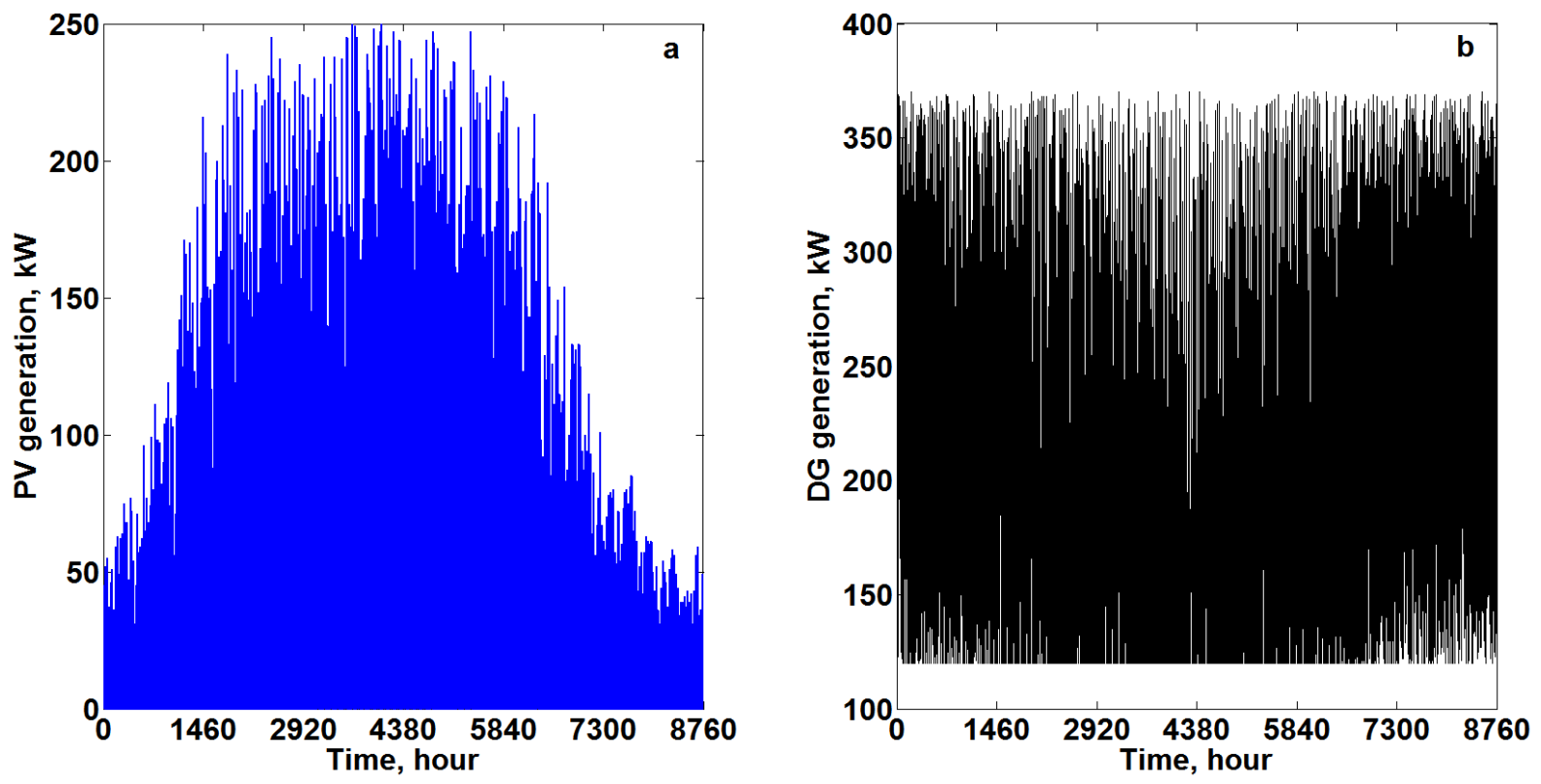

Figure 6. Changes in output power at solar (a) and diesel power plants (b) over a year.

As shown in Figure 6, generation at the solar power plant undergoes considerable changes over a year, whereas the diesel plant's load factor is superior to $30 \%$, which amounts to $120 \mathrm{~kW}$. Peak generation values at the diesel plant are $370 \mathrm{~kW}$.

The generation of the photovoltaic system is 338 thousand $\mathrm{kWh}$ while the diesel station generated 1808 thousand $\mathrm{kWh}$. According to formula 6 number of machine-hours of the diesel power plant is 6465 per year. Taking into account the maintenance schedule for diesel generators, you can determine 
how many times the engine oil has changed, downtime, repairs and the cost of these services. Therefore, this model can also be used in reliability problems of autonomous energy systems.

The diesel plant's output power and load factor values are used to form operating parameters such as rotational speed per minute and specific diesel fuel consumption. Figure 7 shows changes taking place in the operating characteristics of the YaMZ-8503 diesel engine depending on the photovoltaic system's mode of operation.

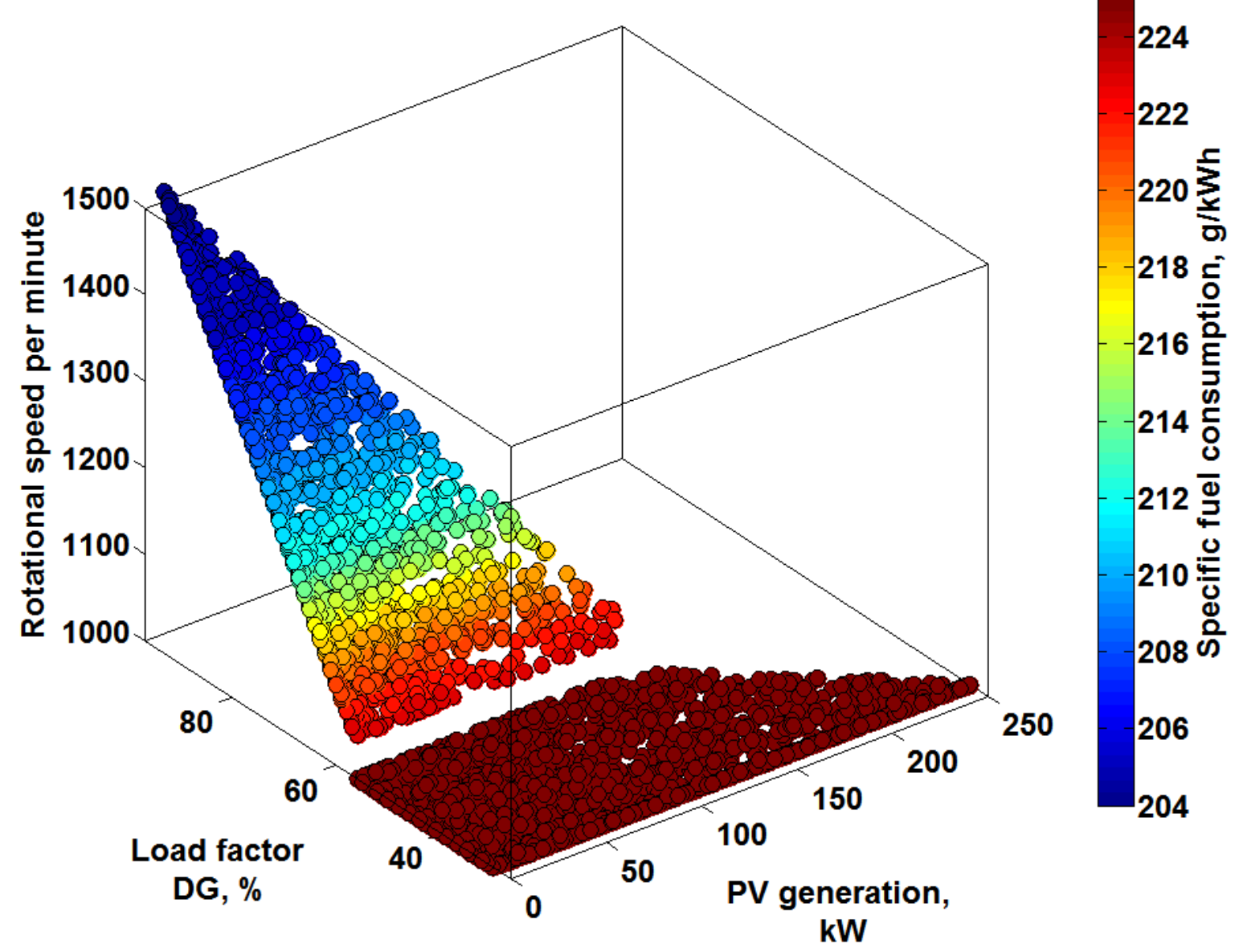

Figure 7. Changes in the operating characteristics of the YaMZ-8503 diesel engine.

As shown in Figure 7, the engine's specific diesel fuel consumption and engine speed depend on the load factor. Importantly, the lesser the diesel generator's load, the lesser engine speed and the higher specific fuel consumption. This testifies to the fact that the diesel power plant's operating parameters based on the engine's speed characteristic have been established correctly and can be used in autonomous power system modelling.

\section{Conclusions}

The diesel generator model described in the present study is universal and compatible with various unit sizes. The speed characteristic of diesel engines serves as a primary reference.

The proposed model can be used to specify the number of machine-hours of units depending on their rotational speed. Consequently, it is possible to take better account of scheduled repairs and maintenance of diesel generators while considering units' not-in-service hours during repairs.

To conclude, this model can be used to ensure the operational safety of photovoltaic systems involving diesel generators and the optimal control of diesel power plants' load factor depending on PV generation by solar power plants. Furthermore, the model under investigation can be part of various equipment optimization solutions. For example, it will be possible to determine the optimal installed power of diesel generators depending on the level of electrical load, the generation of the 
photovoltaic system and the installed capacity of the storage batteries. Moreover, the installed capacity of each unit may be different. For example, in winter, the most powerful diesel generator is used, while in spring and summer two less powerful units are used (main and stand-by unit).

\section{Acknowledgments}

The research was supported by the Program of the Fundamental Research of the Siberian Branch of the Russian Academy of Sciences, project no. III.17.5.1 (reg. no. AAAA-A17-117030310433-6).

\section{Practical application}

This approach was used in the design of the "Verkhnyaya Amga" photovoltaic system located in the Russian Far East. Autonomous photovoltaic system has the following values of installed capacities: $\mathrm{PV}-36 \mathrm{~kW}$; lead-carbon storage batteries $-144 \mathrm{kWh}$; grid-tie inverters $-36 \mathrm{~kW}$; battery inverters $24 \mathrm{~kW}$; two diesel-generators -20 and $25 \mathrm{~kW}$. This autonomous photovoltaic system saves up to $49 \%$ diesel fuel annually.

\section{Further research}

In the future, the authors of the article will investigate the problems of optimizing the composition of the equipment of autonomous energy systems, taking into account issues of electrodynamic stability.

\section{References}

[1] Marchenko O and Solomin S 2017 Modeling of hydrogen and electrical energy storages in wind/PV energy system on the Lake Baikal coast Int. J. Hydrogen Energ. 42 9361-9370

[2] Marchenko O 2010 Mathematical modeling and economic efficiency assessment of autonomous energy systems with production and storage of secondary energy carriers Int. J. Low-Carbon Tec. 5 250-255

[3] Lombardi P, Sokolnikova T, Suslov K, Voropai N and Styczynski Z 2016 Isolated power system in Russia: A chance for renewable energies? Renew Energ. 90 532-541

[4] Ivanova I and Pasechnikov T 2019 Experience of solar-diesel power plant introduction in the village of Nerkha of the Irkutsk region E3S Web Conf. 7704004

[5] Shakirov V 2019 An analysis of wind and solar power variability to assess its implications for power grid EPJ Web Conf. 21701019

[6] Shakirov V 2019 Methodical approach to the estimation of possible energy production by wind and solar power plants using weather station data E3S Web Conf. 7702008

[7] Karamov D and Perzhabinsky S 2018 Influence of failures of overhead lines on reliability of autonomous power supply system E3S Web Conf. 6902015

[8] Sidorov D, Panasetsky D, Tomin N, Karamov D, Zhukov A, Muftahov I, Dreglea A, Liu F, and Li Y 2020 Toward zero-emission hybrid AC/DC power systems with renewable energy sources and storages: A case study from Lake Baikal region Energies 13 ID: 1226

[9] Sidorov D, Muftahov I, Tomin N, Karamov D, Panasetsky D, Dreglea A, Liu F and Foley A 2020 A Dynamic Analysis of Energy Storage with Renewable and Diesel Generation using Volterra Equations IEEE Trans. Ind. Inf. 16 3451-3459

[10] Dufo-López R 2014 Comparison of different lead-acid battery lifetime prediction models for use in simulation of stand-alone photovoltaic systems Appl. Energy 115 242-253

[11] Koehln M, Heck M, Wiesmeier S and Wirth J 2011 Modeling of the nominal operating cell temperature based on outdoor weathering Sol. Energy Mater. Sol. Cells 95 1638-1646

[12] $320 \mathrm{~W}$ heterojunction solar panel [Online]. Available: https://www.hevelsolar.com/en/

[13] Väisänena J, Kosonena A, Aholaa J, Sallinena T and Hannula T 2019 Optimal sizing ratio of a solar PV inverter for minimizing the levelized cost of electricity in Finnish irradiation conditions Sol. Energy 185 350-362.

[14] Diesel engine YaMZ-8503.10 [Online]. Available: https://www.yamz-dizel.ru/enginesyamz/850/8503/ 